\title{
A Simulation Study of Elevator Control of a Building using Digital Logic Circuit
}

\author{
Monzurul Islam Dewan ${ }^{1}$, Md. Arafat Mahmud ${ }^{2}$, Md. Tashfiq Bin Kashem ${ }^{3}$, and \\ Mushfika Baishakhi Upama ${ }^{4}$ \\ ${ }^{1}$ Department of EEE, Ahsanullah University of Science and Technology, Dhaka, Bangladesh \\ ${ }^{2}$ Department of EEE, University of Asia Pacific, Dhaka, Bangladesh \\ ${ }^{3}$ Department of EEE, University of Asia Pacific, Dhaka, Bangladesh \\ ${ }^{4}$ Research and Development Section, Energypac Engineering Ltd., Dhaka, Bangladesh
}

\begin{abstract}
A simulation study of elevator control of a 3-storey building has been presented in this paper. We have focused on logic formulation of the probable events associated with movement of the elevator and implemented the logic equations using standard digital circuit simulator software Proteus 7 Professional. Major sections of the entire circuit structure are input unit, directional control unit, priority encoder, level positioning control unit, output display unit and clock controlling unit. Simulated results from the circuit simulator software show exact match with the desired results which proves our design validity.
\end{abstract}

Keywords: - Latching section, priority encoder, directional control unit, level positioning control unit, Proteus 7 Professional

\section{INTRODUCTION}

Elevator is an inseparable part of a building structure. A simulation study of elevator control of a 3storey building has been presented in this paper using digital logic circuit. Elevator control system of a building has been proposed in some literatures [1][2][3].But, one unique aspect of this work is that we have not included any Microcontroller or Programmable Logic Controller (PLC) for logic implementation in this design, rather we have emphasized on developing logic equations by logic computation and using basic digital logic circuit components. At first, the probable events regarding the up and downwards movement of the elevator have been identified and they have been used as variables to form the logic equation to determine whether the present direction of the lift will be upward or downward. In this logic equation formation, the priority of the events is considered accordingly i.e. the requests have been served on priority basis. Once the direction of the lift is determined, the lift will change its level depending on its current position. The input keys from the elevator users standing inside or outside of the lift and the output display showing present position of the lift have been presented in this paper as observed in a standard 3-storey building elevator. We have used Proteus 7 Professional software to simulate our designed circuit to show its functionality.

II.

SAMPLE INPUTS FROM USERS AND LIST OF EVENTS

A. SAMPLE INPUTS

Inputs offered to an elevator user standing inside or outside of a 3-storey building elevator have been displayed in Table I:

TABLE I: SAMPLE INPUTS AND REQUESTED INSTRUCTIONS

\begin{tabular}{|c|c|c|}
\hline Position of the user & Symbol & Requested Instruction \\
\hline Inside the elevator & GF & To go to ground floor \\
\hline Inside the elevator & To go to $1^{\text {st }}$ floor \\
\hline Inside the elevator & 2F & To go to $2^{\text {nd }}$ floor \\
\hline Outside the elevator & G_UP & To go upwards from ground floor \\
\hline Outside the elevator & 1_DOWN & To go downwards from $1^{\text {st }}$ floor \\
\hline Outside the elevator & 1_UP & To go upwards from $1^{\text {st }}$ floor \\
\hline Outside the elevator & 2_DOWN & To go downwards from $2^{\text {nd }}$ floor \\
\hline
\end{tabular}

\section{B. LIST OF EVENTS}

Events that can take place in operation of a 3-storey building elevator are listed in Table II: 
TABLE II: LIST OF EVENTS AT DIFFERENT ELEVATOR POSITION

\begin{tabular}{|c|c|c|}
\hline $\begin{array}{l}\text { Position of } \\
\text { the elevator }\end{array}$ & Symbol & Event \\
\hline \multirow{5}{*}{$\begin{array}{l}\text { At ground } \\
\text { floor }\end{array}$} & \multirow[t]{5}{*}{ STATUS_GROUND } & $1 \mathrm{~F}$ is pressed from inside \\
\hline & & $2 \mathrm{~F}$ is pressed from inside \\
\hline & & 1_DOWN is pressed from outside \\
\hline & & 1_UP is pressed from outside \\
\hline & & 2_DOWN is pressed from outside \\
\hline \multirow[t]{4}{*}{ At $1^{\text {st }}$ floor } & \multirow[t]{4}{*}{ STATUS_1ST } & GF is pressed from inside \\
\hline & & $2 \mathrm{~F}$ is pressed from inside \\
\hline & & G_UP is pressed from outside \\
\hline & & 2_DOWN is pressed from outside \\
\hline \multirow[t]{5}{*}{ At $2^{\text {nd }}$ floor } & \multirow[t]{5}{*}{ STATUS_2ND } & GF is pressed from inside \\
\hline & & $1 \mathrm{~F}$ is pressed from inside \\
\hline & & 1_UP is pressed from outside \\
\hline & & 1_DOWN is pressed from outside \\
\hline & & G_UP is pressed from outside \\
\hline
\end{tabular}

\section{LOGIC EQUATIONS}

Developing logic equations for determining the position of the elevator requires three steps logic formulation : at first, setting the direction of the elevator at an instant i.e. whether the elevator will move up or downwards at an instant and secondly setting the priority of the events associated with each of the directional movements and finally, determining the current position of the elevator.

\section{A. LOGIC FORMULATION OF ELEVATOR DIRECTION}

We denote the event of upward and downward direction of an elevator at an instant to be Y0 and $\mathrm{Y} 1$ respectively. So, the expression of Y0 and Y1 should be :

$$
\begin{aligned}
& \text { Y0=STATUS_GROUND+(2_DOWN+2F). } \bar{Y} 1 \text {.(STATUS_1ST) +STATUS_1ST.(2_DOWN+2F).1_UP } \\
& \mathrm{Y} 1=\left[\mathrm{STATUS} \_1 \mathrm{ST} .\left(\mathrm{G} \_\mathrm{UP}+\mathrm{GF}\right) . \overline{\mathrm{Y} 0}+\left(\mathrm{G} \_\mathrm{UP}+\mathrm{GF}\right)+\mathrm{STATUS} \_1 \mathrm{ST} .\left(2 \_\mathrm{DOWN}+2 \mathrm{~F}\right) .1 \_\mathrm{DOWN}+\mathrm{STATUS} \_2 \mathrm{ND}\right] . \overline{\mathrm{Y} 0}
\end{aligned}
$$

\section{B. LOGIC FORMULATION OF PRIORITY OF EVENTS}

After the direction of the elevator is determined, the priority of all the events associated with that direction must be set to determine the current position of the elevator. Priority list of the events in each of the directional movements of the elevator is given in Table III:

\begin{tabular}{|c|c|c|}
\hline Direction of the elevator & Logic state & Events arranged in descending order of priority \\
\hline \multirow[t]{5}{*}{ Upward } & \multirow[t]{5}{*}{$\mathrm{Y} 0=1, \mathrm{Y} 1=0$} & $1 \mathrm{~F}$ \\
\hline & & 1_UP \\
\hline & & $2 \mathrm{~F}$ \\
\hline & & 2_DOWN \\
\hline & & 1_DOWN \\
\hline \multirow[t]{5}{*}{ Downward } & \multirow[t]{5}{*}{$\mathrm{Y} 0=0, \mathrm{Y} 1=1$} & $1 \mathrm{~F}$ \\
\hline & & 1_DOWN \\
\hline & & GF \\
\hline & & G_UP \\
\hline & & 1_UP \\
\hline
\end{tabular}

TABLE III: PRIORITY OF EVENTS AT DIFFERENT ELEVATOR DIRECTIONS

So, the truth table of the priority encoder for upward direction can be given in Table IV:

TABLE IV: TRUTH TABLE OF THE PRIORITY ENCODER FOR UPWARD DIRECTION

\begin{tabular}{|c|c|c|c|c|c|c|c|}
\hline 1_DOWN & $2 \_D O W N$ & $2 \mathrm{~F}$ & 1_UP & 1F & Q2 & Q1 & Q0 \\
\hline $\mathrm{x}$ & $\mathrm{x}$ & $\mathrm{x}$ & $\mathrm{x}$ & 1 & 1 & 1 & 1 \\
\hline $\mathrm{x}$ & $\mathrm{x}$ & $\mathrm{x}$ & 1 & 0 & 1 & 1 & 0 \\
\hline $\mathrm{x}$ & $\mathrm{x}$ & 1 & 0 & 0 & 1 & 0 & 1 \\
\hline $\mathrm{x}$ & 1 & 0 & 0 & 0 & 1 & 0 & 0 \\
\hline 1 & 0 & 0 & 0 & 0 & 0 & 1 & 1 \\
\hline
\end{tabular}


The logic function for Q2, Q1 and Q0 thus can be written as:

$$
\begin{aligned}
& \mathrm{Q} 2=1 \mathrm{~F}+1 \_\mathrm{UP} \cdot(\overline{1 \mathrm{~F}})+2 \mathrm{~F} \cdot\left(\overline{1 \_U P}\right) \cdot(\overline{1 \mathrm{~F}})+2 \_\mathrm{DOWN} \cdot(\overline{2 \mathrm{~F}}) \cdot\left(\overline{1 \_U P}\right) \cdot(\overline{\mathrm{1F}}) \\
& \mathrm{Q} 1=1 \mathrm{~F}+1 \_\mathrm{UP} \cdot(\overline{\mathrm{1F}})+1 \_\mathrm{DOWN} \cdot\left(\overline{2 \_\mathrm{DOWN}}\right) \cdot(\overline{2 \mathrm{~F}}) \cdot\left(\overline{1 \_U P}\right) \cdot(\overline{1 \mathrm{~F}}) \\
& \mathrm{Q} 0=1 \mathrm{~F}+2 \mathrm{~F} \cdot\left(\overline{1 \_U P}\right) \cdot(\overline{1 \mathrm{~F}})+1 \_\mathrm{DOWN} \cdot\left(\overline{2 \_\mathrm{DOWN}}\right) \cdot(\overline{2 \mathrm{~F}}) \cdot\left(\overline{1 \_U P}\right) \cdot(\overline{1 \mathrm{~F}})
\end{aligned}
$$

The truth table of the priority encoder for downward direction can be given in Table V:

TABLE V: TRUTH TABLE OF THE PRIORITY ENCODER FOR DOWNWARD DIRECTION

\begin{tabular}{|c|c|c|c|c|c|c|c|}
\hline 1_UP & G_UP & GF & 1_DOWN & 1F & Q2 & Q1 & Q0 \\
\hline $\mathrm{X}$ & $\mathrm{x}$ & $\mathrm{x}$ & $\mathrm{x}$ & 1 & 1 & 1 & 1 \\
\hline $\mathrm{X}$ & $\mathrm{X}$ & $\mathrm{x}$ & 1 & 0 & 1 & 1 & 0 \\
\hline $\mathrm{X}$ & $\mathrm{X}$ & 1 & 0 & 0 & 1 & 0 & 1 \\
\hline $\mathrm{X}$ & 1 & 0 & 0 & 0 & 1 & 0 & 0 \\
\hline 1 & 0 & 0 & 0 & 0 & 0 & 1 & 1 \\
\hline
\end{tabular}

The logic function for Q2, Q1 and Q0 thus can be written as:

$$
\begin{aligned}
& \mathrm{Q} 2=1 \mathrm{~F}+1 \_ \text {DOWN } \cdot(\overline{\mathrm{1F}})+\mathrm{GF} \cdot\left(\overline{1 \_D O W N}\right) \cdot(\overline{\mathrm{1F}})+\mathrm{G} \_\mathrm{UP} \cdot(\overline{\mathrm{GF}}) \cdot\left(\overline{\overline{1} \_\mathrm{DOWN}}\right) \cdot(\overline{\mathrm{1F}}) \\
& \mathrm{Q} 1=1 \mathrm{~F}+1 \_D O W N \cdot(\overline{\mathrm{1F}})+1 \_\mathrm{UP} \cdot\left(\overline{\mathrm{G} \_\mathrm{UP}}\right) \cdot(\overline{\mathrm{GF}}) \cdot\left(\overline{1 \_D O W N}\right) \cdot(\overline{\mathrm{IF}}) \\
& \mathrm{Q} 0=1 \mathrm{~F}+\mathrm{GF} \cdot\left(\overline{1 \_D O W N}\right) \cdot(\overline{\mathrm{IF}})+1 \_\mathrm{UP} \cdot\left(\overline{\mathrm{G} \_\mathrm{UP}}\right) \cdot(\overline{\mathrm{GF}}) \cdot\left(\overline{1 \_D O W N}\right) \cdot(\overline{1 F})
\end{aligned}
$$

\section{LOGIC FORMULATION OF ELEVATOR POSITION}

Outputs from the encoder are passed to a decoder and the decoder outputs (Y7,Y6,Y5,Y4) are used for forming logic equation to find the current elevator position. The three binary bits S2, S1 and S0 denote the position of the elevator. Corresponding truth tables for up and downward direction are presented in Table VI and VII:

TABLE VI: TRUTH TABLE OF ELEVATOR POSITION FOR UPWARD DIRECTION(Y0=1, Y1=0)

\begin{tabular}{|c|c|c|c|c|c|c|c|c|c|c|}
\hline Q2 & Q1 & Q0 & Y7 & Y6 & Y5 & Y4 & S2 & S1 & S0 & Position \\
\hline 1 & 1 & 1 & 1 & 0 & 0 & 0 & 0 & 0 & 1 & $1^{\text {st }}$ Floor \\
\hline 1 & 1 & 0 & 0 & 1 & 0 & 0 & 0 & 0 & 1 & $1^{\text {st }}$ Floor \\
\hline 1 & 0 & 1 & 0 & 0 & 1 & 0 & 1 & 0 & 0 & $2^{\text {nd }}$ Floor \\
\hline 1 & 0 & 0 & 0 & 0 & 0 & 1 & 1 & 0 & 0 & $2^{\text {nd }}$ Floor \\
\hline
\end{tabular}

So, the expression of $\mathrm{S} 2$ and $\mathrm{S} 0$ can be given by :

$$
\begin{aligned}
& \mathrm{S} 2=(\mathrm{Y} 4+\mathrm{Y} 5) \cdot \mathrm{Y} 0 \cdot \overline{\mathrm{Y} 1} \\
& \mathrm{~S} 1=(\mathrm{Y} 6+\mathrm{Y} 7) \cdot \mathrm{Y} 0 \cdot \overline{\mathrm{Y} 1}
\end{aligned}
$$

TABLE VI: TRUTH TABLE OF ELEVATOR POSITION FOR DOWNWARD DIRECTION(Y0=0, Y1=1)

\begin{tabular}{|c|c|c|c|c|c|c|c|c|c|c|}
\hline Q2 & Q1 & Q0 & Y7 & Y6 & Y5 & Y4 & S2 & S1 & S0 & Position \\
\hline 1 & 1 & 1 & 1 & 0 & 0 & 0 & 0 & 0 & 1 & $1^{\text {st }}$ Floor \\
\hline 1 & 1 & 0 & 0 & 1 & 0 & 0 & 0 & 0 & 1 & $1^{\text {st }}$ Floor \\
\hline 1 & 0 & 1 & 0 & 0 & 1 & 0 & 1 & 0 & 0 & Ground Floor \\
\hline 1 & 0 & 0 & 0 & 0 & 0 & 1 & 1 & 0 & 0 & Ground Floor \\
\hline
\end{tabular}

So, the expression of $\mathrm{S} 1$ and $\mathrm{S} 0$ can be given by :

$$
\begin{aligned}
& \mathrm{S} 1=(\mathrm{Y} 6+\mathrm{Y} 7) \cdot \mathrm{Y} 1 \cdot \overline{\mathrm{Y} 0} \\
& \mathrm{~S} 0=(\mathrm{Y} 4+\mathrm{Y} 5) \cdot \mathrm{Y} 1 \cdot \overline{\mathrm{Y} 0}
\end{aligned}
$$

The overall expression is :

$$
\begin{gathered}
\mathrm{S} 0=(\mathrm{Y} 4+\mathrm{Y} 5) \cdot \mathrm{Y} 1 \cdot \overline{\mathrm{Y} 0} \\
\mathrm{~S} 1=(\mathrm{Y} 6+\mathrm{Y} 7) \cdot \mathrm{Y} 0 \cdot \overline{\mathrm{Y}} 1+(\mathrm{Y} 6+\mathrm{Y} 7) \cdot \mathrm{Y} 1 \cdot \overline{\mathrm{Y} 0}
\end{gathered}
$$




$$
\mathrm{S} 2=(\mathrm{Y} 4+\mathrm{Y} 5) \cdot \mathrm{Y} 0 \cdot \overline{\mathrm{Y} 1}
$$

\section{CIRCUIT DESIGN DESCRIPTION}

In this section, the entire circuit design architecture has been described section wise. Fig. 1 shows the total circuit diagram. Several literatures on elevator design architecture have divided their design in some sections and subsections to explain their functionality clearly[4][5].Our proposed design architecture can grossly be divided into five sections: Input unit, Directional control unit, Priority Encoder, Level positioning control unit, Output display unit and clock controlling unit

\section{A. INPUT UNIT}

Input unit consists of two major subsections: Request receiving section and latching section. The requests listed in Table I are taken from the user using LOGICTOGGLE available at Proteus 7 Professional. They serve as the request receiving section of the input unit. They can provide a single pulse to request an event. Fig. 2 shows this sub-section. Since a number of instructions can be requested simultaneously and they must be served on priority basis, so the rest of the instructions must be saved using a latching section. In our design, we have used J-K flip-flops as the latching section. Since the two inputs of the flip-flops are shorted together and assigned a constant logic level 1 , so it essentially works as a $\mathrm{T}$ flip flop. The inputs from the request receiving section work as the clock of the flip-flops. If any particular request is made twice consecutively, the clock pulse of the flip-flops works the same way consecutively and because of the consecutive toggling of data at J-K flipflop, that particular request is reset. It resembles to an event if a user mistakenly requests an event and wants to cancel the request by pressing the request button for the second time. The latching section has been illustrated in Fig. 3.

\section{B. DIRECTIONAL CONTROL UNIT}

Directional control unit consists of a logic circuit implementing the logic equations described at Eq. 12. This unit determines the up or downward direction of the lift at an instant. The outputs of this unit, Y0 and Y1 are used as the enablers of the buffers used to pass the level positioning data to the central bus. These buffers are used to avoid the race condition (two logic levels at the same node) since at each instant Y0 and Y1 values are updated according to logic Eq. 1-2 and only one of them should send level positioning data to bus. This control unit has been presented in Fig. 4.

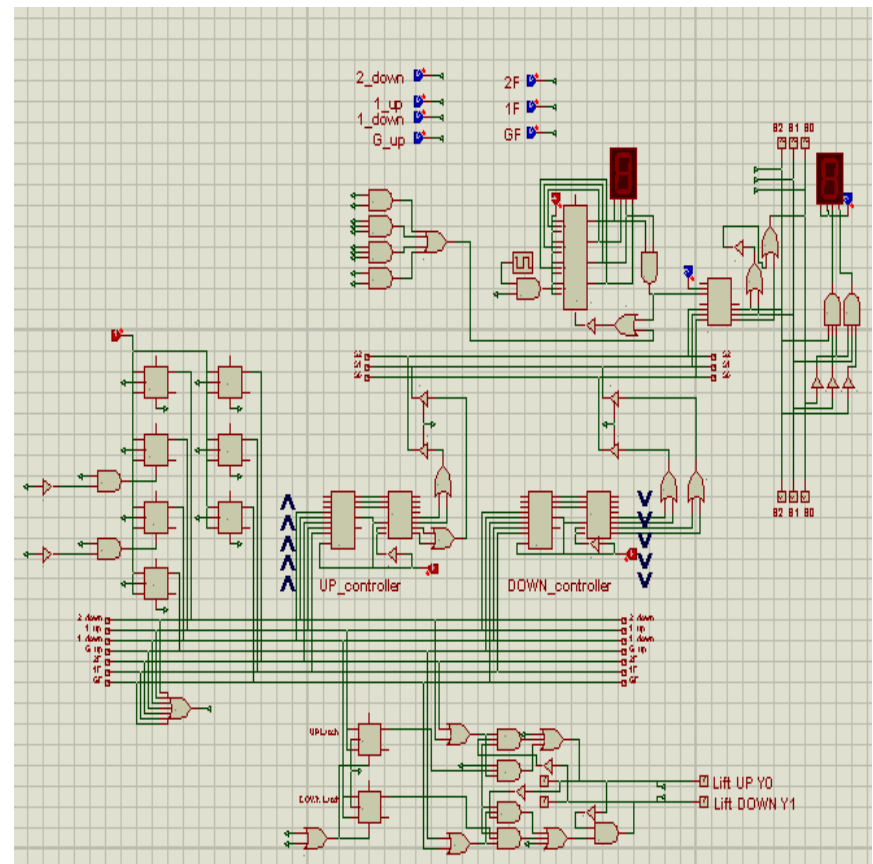

Fig. 1. Total circuit architecture of the elevator control design 


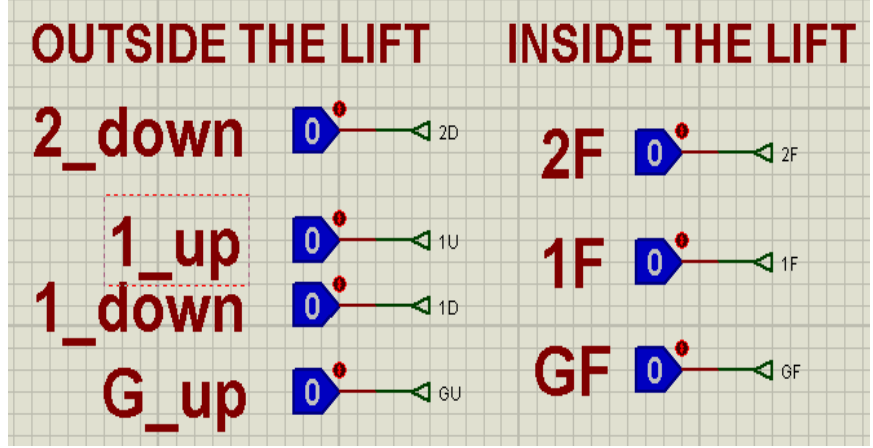

Fig. 2. Request receiving section

\section{PRIORITY ENCODER}

After the direction of the movement of the lift is decided, the next step is to set the priority of the requests stored in the latching section. Priority encoder serves this purpose. Two priority encoders have been used to assign the priority of the events listed in Table III associated with both the upward and the downward direction of the elevator. The 3 bit outputs from both the priority encoder helps to build the level positioning control unit to determine the current position of the lift. Fig. 5 shows the priority encoder section of the circuit design.

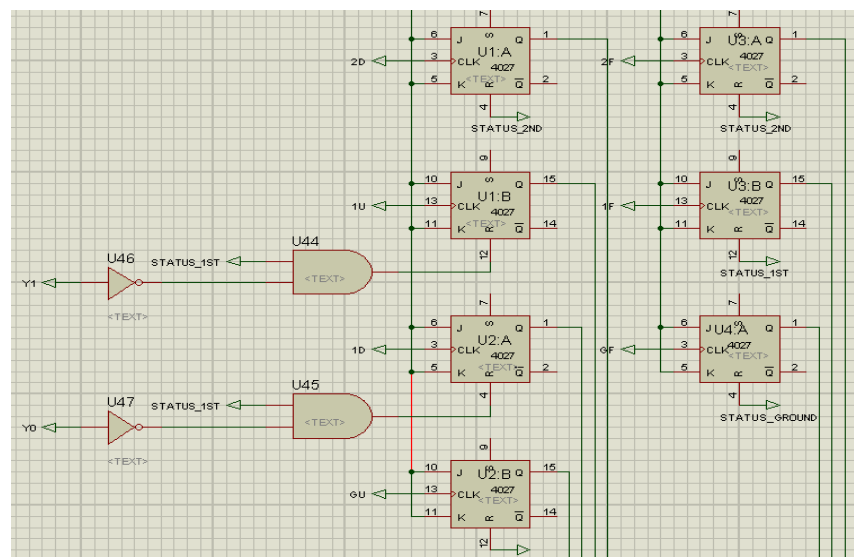

Fig. 3. Latching Section

\section{LEVEL POSITIONING CONTROL UNIT}

Level positioning control unit consists of two decoders and buffer circuits. This is the unit which determines the current level position and sends the data to central bus to display it to the output section. This section is guided by the logic equations presented at Eqs. 13-15. S2, S1 and S0 denote the current level position of the elevator. Buffers are enabled by logic state of $\mathrm{Y} 0$ and $\mathrm{Y} 1$ so that two different logic level are not encountered at central bus. The Fig. 6 shows the level positioning control unit.

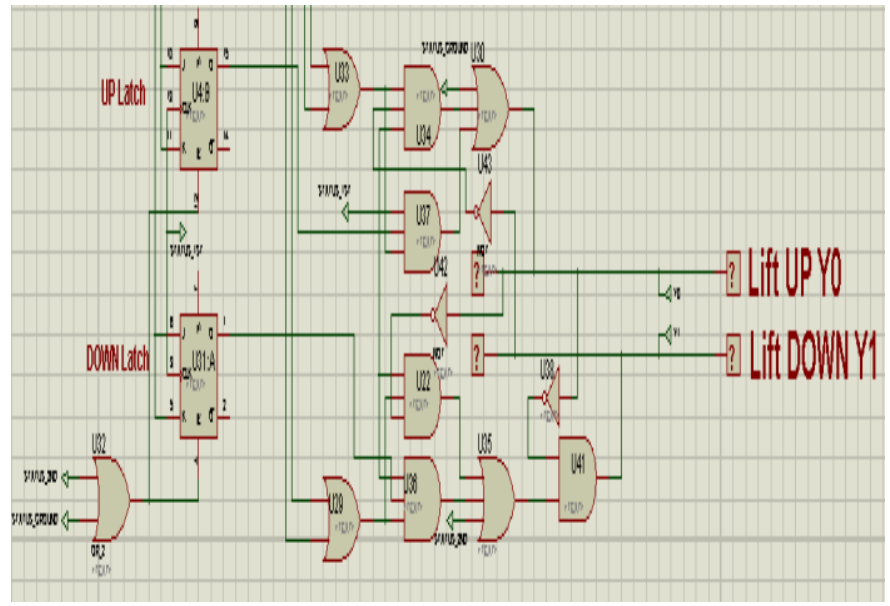

Fig. 4. Directional control unit 


\section{E. OUTPUT DISPLAY UNIT}

Current level position determined by the level positioning control unit will be displayed in the output display. Since the requests are served consecutively, the level positions output from the level positioning control unit are first set as input(S2, S1 and S0) of a register and they are sent to final output display(s2, s1 and s0) with a fixed delay between consecutive outputs. This fixed delay is set by a clocking control unit. Final output display is shown in a BCD 7-segment display. Fig. 7 shows the output display unit.

\section{F. CLOCK CONTROL UNIT}

Clock controlling unit controls fixed delay between consecutive requests. Successive requests are served with a 10 s delay in between them which resemble to transition of the elevator between the floors. This control unit is shown in Fig. 8.

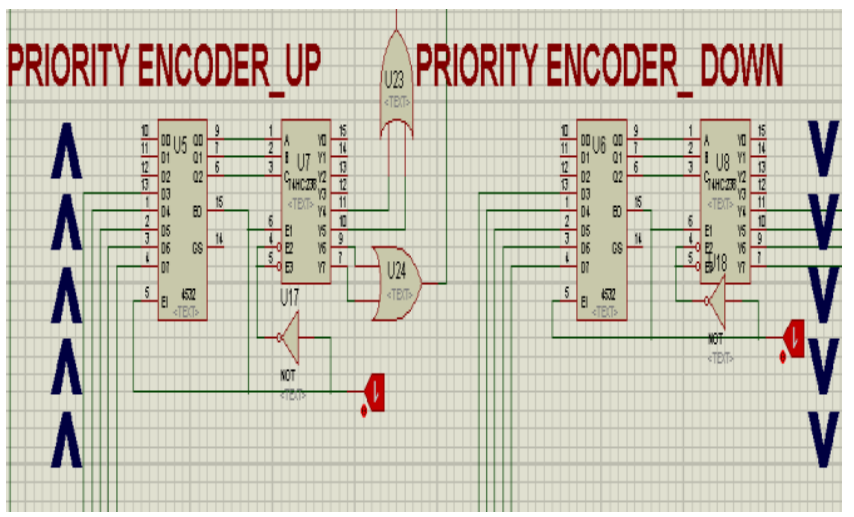

Fig. 5. Priority encoder

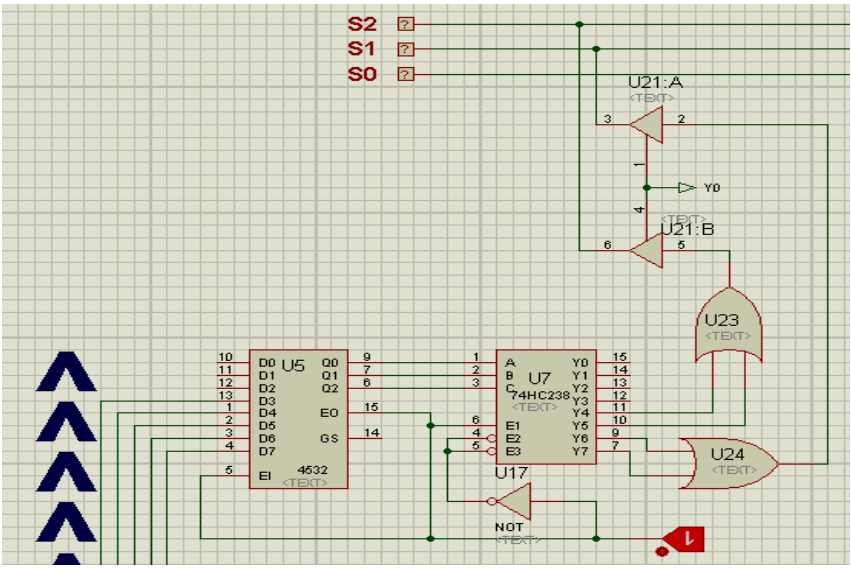

Fig. 6. Level positioning control unit

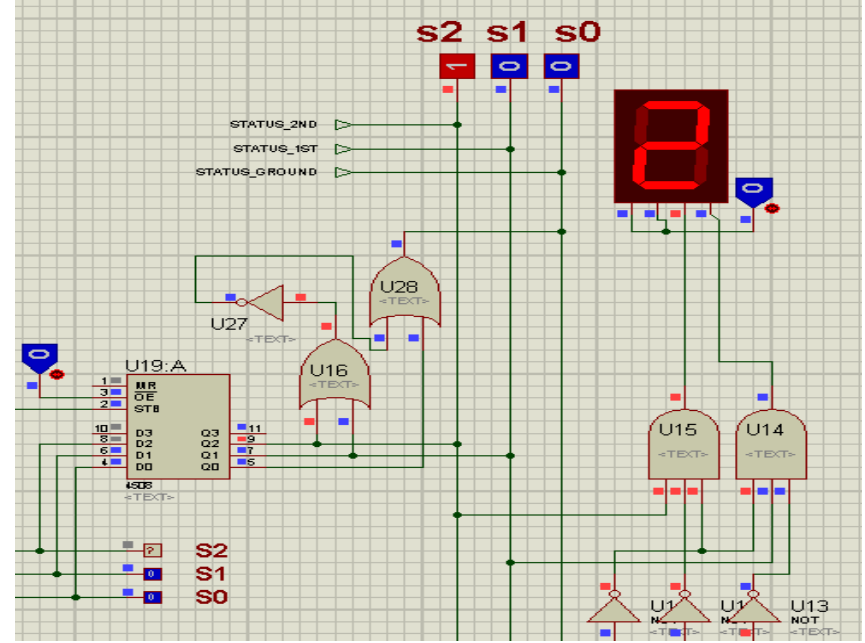

Fig. 7. Output display unit 


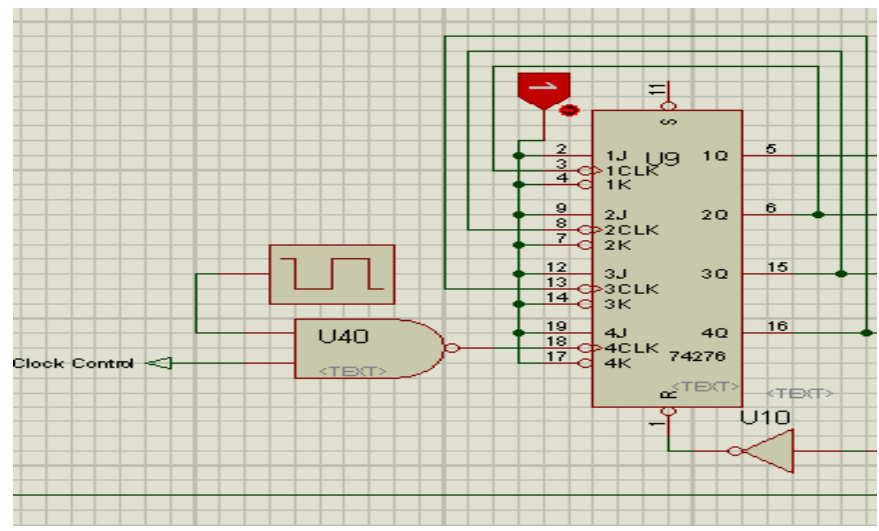

Fig. 8. Clock controlling unit

V. FUNCTIONAL BLOCK DIAGRAM

The entire functional block diagram of the elevator control circuit can be presented as Fig. 8 .

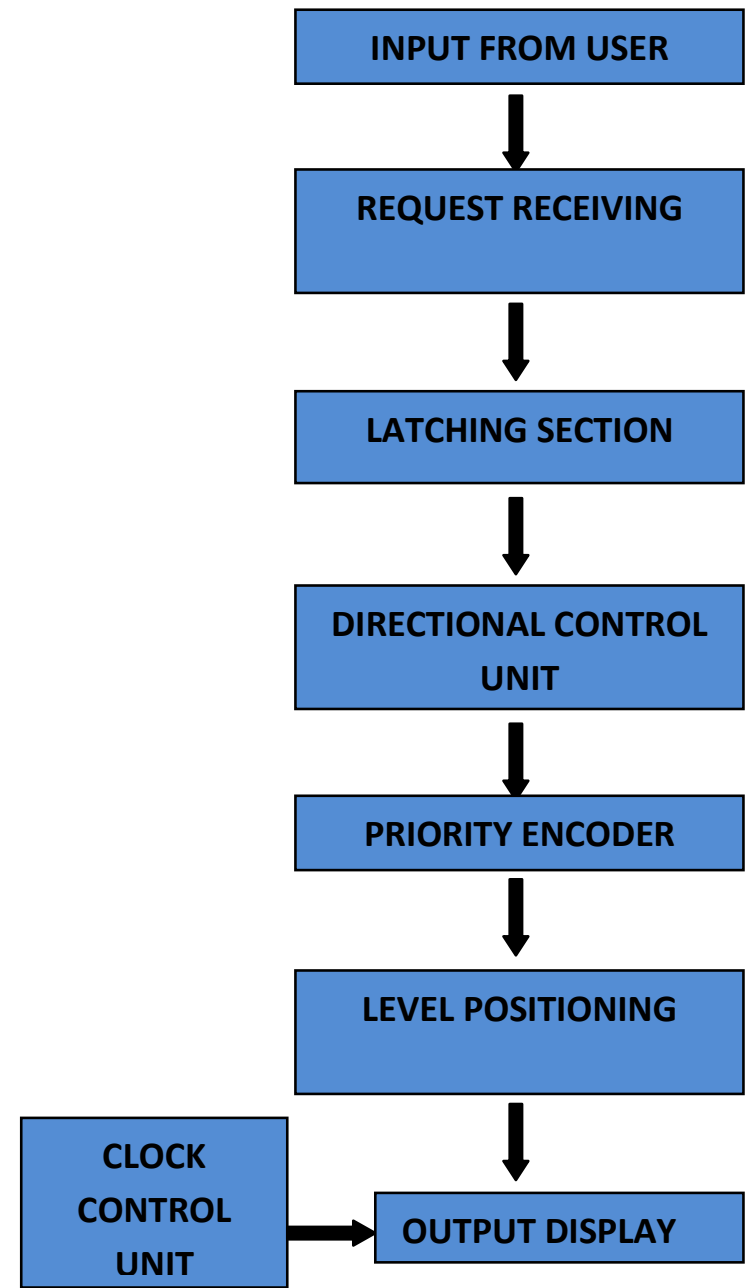

Fig. 8. Functional block diagram of the elevator control circuit

\section{CONCLUSION}

A digital logic circuit based elevator control system design of a 3-storey building has been presented in this paper. Considering the probable events, associated with the movement of the elevator, as variables, logic formulation has been done. Based on those logic equations, the circuit has been simulated with appropriate circuit components available at Proteus 7 Professional software package. We have obtained desired output at the output display section which proves the validity of our proposed circuit design. 


\section{ACKNOWLEDGMENT}

We would like to express our gratitude to our respected teacher Mr. Zunaid Baten, Lecturer, Department of EEE, BUET, who inspired and motivated us to get ourselves involved in innovative circuit design.

\section{REFERENCES}

[1] S. B. R. Carter, and A. Selvaraj, "Design and implementation of PLC based elevator," FInternational journal of computer applications, vol. 68, no. 7, pp. 88-92, 2013.

[2] K. M. K. S. Bandara, S. G. Aberathne, and S. D. Dewasurendra, "Statechart based elevator controller and its verification," First international conference on industrial and information systems, pp. 88-92, August 2006.

[3] S. Huseinbegovic, S. Kreso, and O. Tanovic, "Design and implementation of the CAN based elevator control system," XXII international symposium on information, communication and automation technologies, pp. 1-6, October 2009.

[4] C. Y. Lin, M. Wu, J. A. Bloom, I. J. Cox, and M. Miller, "Modeling of an elevator group control system using programmable logic control and destination control system," ABCM symposium series on mechatronics., vol. 4, pp. 433-441, 2010.

[5] A. S. Naumov, and A. A. Shalyto, Elevator control system:object-oriented programming with explicit state selection, St. Petersburg state institute of fine mechanics and optics, St. Petersburg.: 2003 